\title{
Supporting Information for: One-Step Synthesis and Characterization of Difunctionalized N-Confused Tetraphenylporphyrins
}

\author{
Shana A. Wolff ${ }^{\S}$ Elvin A. Alemán ${ }^{\S}$, Debasish Banerjee ${ }^{\dagger}$, Peter L. Rinaldi ${ }^{\dagger}$, and David A. \\ Modarelli* ${ }^{\mathcal{S}}$ \\ Department of Chemistry, Molecular Spectroscopy Laboratory and The Center for Laser and \\ Optical Spectroscopy, Knight Chemical Laboratory, The University of Akron, Akron, Ohio \\ 44325-3601
}

25 PAGES

\section{TABLE OF CONTENTS}

1) General experimental methods (S2).

2) Experimental procedures for the synthesis of 5,10,15,20-tetrakis(3,5-di-tert-butylphenyl) $\mathrm{N}$ confused porphyrin and $\mathrm{H}_{2} \mathrm{Br}_{4} \mathrm{NCTPP}(\mathrm{S} 3-\mathrm{S} 4)$.

3) Description of 1-D and 2-D NMR methodologies (S5).

4) Detailed interpretation of the one- and two-dimensional (gHMQC and gHMBC) NMR spectra shown in Figures S1 - S3 (S6 - S10).

5) ${ }^{1} \mathrm{H}-\mathrm{NMR}$ and ${ }^{13} \mathrm{C}$-NMR spectra of porphyrins $\mathbf{2}-\mathbf{4}, 5,10,15,20$-tetrakis(3,5-di-tertbutylphenyl) $\mathrm{N}$-confused porphyrin and $\mathrm{H}_{2} \mathrm{Br}_{4} \mathrm{NCTPP}$ in $\mathrm{CDCl}_{3}$. Acquisition of the ${ }^{13} \mathrm{C}-\mathrm{NMR}$ spectrum of $\mathrm{H}_{2} \mathrm{Br}_{4} \mathrm{NCTPP}$ was not possible because of low solubility (S11 - S19).

6) High resolution TOF-ESI-MS spectra of porphyrins $\mathbf{2}-\mathbf{4}$, 5,10,15,20-tetrakis(3,5-di-tertbutylphenyl) $\mathrm{N}$-confused porphyrin and $\mathrm{H}_{2} \mathrm{Br}_{4} \mathrm{NCTPP}(\mathrm{S} 20-\mathrm{S} 25)$. 
General Methods. All reactions were run under a nitrogen atmosphere unless indicated otherwise. Pyrrole was distilled from $\mathrm{CaH}_{2}$, while all other solvents were used as received. All starting materials were used as received. Flash chromatography was carried out on silica gel (230-400 mesh) or basic alumina (60-325 mesh). Absorption and fluorescence experiments were carried out as described previously. ${ }^{1}$ Steady state fluorescence spectra were collected using argon-saturated solutions by exciting at the Soret maxima of optically matched samples (OD 0.20) in S/R mode to correct for changes in the lamp output intensity. Quantum yield measurements were made relative to $\mathrm{H}_{2} \mathrm{TPP}^{2}$ Slits were set to $1.0 \mathrm{~mm}$ for the entrance, $1.0 \mathrm{~mm}$ for the intermediate and $1.3 \mathrm{~mm}$ for the exit excitation slits, and $1.5 \mathrm{~mm}$ for the entrance, $2.3 \mathrm{~mm}$ for the exit and $2.0 \mathrm{~mm}$ for the intermediate emission slits. All solvents used for spectroscopic measurements were spectrophotometric grade and were used as received.

All high resolution MS experiments were performed on a LC-TOF mass spectrometer equipped with an orthogonal electrospray source (Z-spray) operated in positive ion mode. Sodium iodide was used for mass calibration for a calibration range of m/z $100-2000$. NCPs 2 - 4, $\mathbf{H}_{2} \mathbf{B u}_{8} \mathbf{N C T P P}$, and $\mathbf{H}_{2} \mathbf{B r}_{4} \mathbf{N C T P P}$ were prepared in a solution containing $50 \%$ methanol/1\% acetic acid infused into the electrospray source at a rate of $5-10 \mathrm{~mL} \mathrm{~min}{ }^{-1}$. Optimal ESI conditions were found to use a capillary voltage of $3000 \mathrm{~V}$, a source temperature of $110^{\circ} \mathrm{C}$, and a cone voltage of $60 \mathrm{~V}$. Data was acquired in continuum mode until acceptable averaged data was obtained. 


\section{General Method for the synthesis of 5,10,15,20-Tetrasubstituted N-Confused Porphyrins:}

To a $1 \mathrm{~L}$ round bottom three-neck flask, the appropriate aldehyde $(6.0 \mathrm{mmol})$ and pyrrole $(6.0$ $\mathrm{mmol})$ were dissolved in $600 \mathrm{~mL}$ dichloromethane. Methane sulfonic acid (4.2 mmol, $0.27 \mathrm{~mL})$ was then added slowly and the reaction was allowed to stir for $30 \mathrm{~min}$. DDQ (5.3 mmol, $1.2 \mathrm{~g}$ ) was added all at once and the reaction stirred 10 min more and was then quenched with triethylamine $(2.0 \mathrm{~mL})$. The crude mixture was filtered through activity III basic alumina (200 g), flushed with a solution of $\mathrm{CH}_{2} \mathrm{Cl}_{2}$ :TEA (99:1) and concentrated under vacuum. Column chromatography on silica using $100 \% \mathrm{CH}_{2} \mathrm{Cl}_{2}$ removed the porphyrin, followed by a gradual increase of methanol to remove the $\mathrm{N}$-confused porphyrin.

\section{5,10,15,20-(3,5-di-tert-butylphenyl) $\mathrm{N}$-confused porphyrin ${ }^{3}\left(\mathrm{H}_{2} \mathrm{Bu}_{8} \mathrm{NCTPP}\right)$}

The crude $\mathrm{N}$-confused porphryin was chromatographed on activity III basic alumina (70:30 hexanes: $\mathrm{CH}_{2} \mathrm{Cl}_{2}$ ) and recrystallized from $\mathrm{CH}_{2} \mathrm{Cl}_{2}$ and $\mathrm{CH}_{3} \mathrm{CN}$ to yield a purplish solid (10\%). ${ }^{1} \mathrm{H}$ NMR (300 MHz, $\left.\mathrm{CDCl}_{3}, \delta\right)-5.02(\mathrm{~s}, 1 \mathrm{H}),-2.36(\mathrm{bs}, 2 \mathrm{H}), 1.56(\mathrm{~d}, 72 \mathrm{H}, J=19.5 \mathrm{~Hz}), 7.80(\mathrm{~m}$, 4H), $8.03(\mathrm{~s}, 4 \mathrm{H}), 8.20(\mathrm{~d}, 4 \mathrm{H}, J=14.0 \mathrm{~Hz}), 8.66(\mathrm{~m}, 4 \mathrm{H}), 8.83(\mathrm{~s}, 1 \mathrm{H}), 8.93(\mathrm{~d}, 1 \mathrm{H}, J=4.27$ $\mathrm{Hz}), 9.02(\mathrm{~d}, 1 \mathrm{H}, J=4.89 \mathrm{~Hz}) ;{ }^{13} \mathrm{C} \mathrm{NMR}\left(75 \mathrm{MHz}, \mathrm{CDCl}_{3}, \delta\right)$ 31.68, 32.02, 35.37, 99.50, $120.15,121.29,121.96,122.18,125.90,126.57,128.55,129.69,129.74,132.04,132.19,134.88$, $135.35,137.46,137.69,139.29,139.45,140.00,140.52,141.24,149.08,149.19,149.95,156.38$; TOF-MS (ES $\left.{ }^{+}\right) \mathrm{C}_{76} \mathrm{H}_{94} \mathrm{~N}_{4}$ calculated $\mathrm{m} / z$ 1063.7556, observed $m / z$ 1063.7544 [M] $\mathrm{H}^{+}$; UV-VIS $\left(\mathrm{CH}_{2} \mathrm{Cl}_{2}, \mathrm{~nm}\right) 441,543,585,672$ and 728.

\section{5,10,15,20-(4-bromophenyl) $\mathrm{N}$-confused porphyrin $\left(\mathrm{H}_{2} \mathrm{Br}_{4} \mathrm{NCTPP}\right)$}

Recrystallization with $\mathrm{CH}_{2} \mathrm{Cl}_{2}$ and hexanes yielded a purplish solid (13\%). ${ }^{1} \mathrm{H}$ NMR (300 $\left.\mathrm{MHz}, \mathrm{CDCl}_{3}, \delta\right)-5.07(\mathrm{~s}, 1 \mathrm{H}),-2.53(\mathrm{bs}, 2 \mathrm{H}), 7.91(\mathrm{~m}, 4 \mathrm{H}), 8.01(\mathrm{~m}, 8 \mathrm{H}), 8.21(\mathrm{~m}, 4 \mathrm{H}), 8.59(\mathrm{~m}$, 
4H), $8.74(\mathrm{~s}, 1 \mathrm{H}), 8.93(\mathrm{~d}, 1 \mathrm{H}, J=4.88 \mathrm{~Hz}), 8.97(\mathrm{~d}, 1 \mathrm{H}, J=4.27 \mathrm{~Hz})$; TOF-MS $\left(\mathrm{ES}^{+}\right)$ $\mathrm{C}_{44} \mathrm{H}_{26} \mathrm{~N}_{4} \mathrm{Br}_{4}$ calculated $m / z$ 930.8929, observed $m / z$ 930.8860 [M] $\mathrm{H}^{+}$; UV-VIS $\left(\mathrm{CH}_{2} \mathrm{Cl}_{2}, \mathrm{~nm}\right) 441$, 542, 585, 675 and 728. 
$1 D$ NMR experiments. All the NMR experiments were performed on a $750 \mathrm{MHz}$ spectrometer at $30^{\circ} \mathrm{C}$ unless otherwise noted. To acquire the ${ }^{1} \mathrm{H}$ spectrum 16 transients were averaged using an $11.5 \mu \mathrm{s} 90^{\circ}$ pulse over a spectral width of $12001.2 \mathrm{~Hz}$. The ${ }^{13} \mathrm{C}$ NMR was obtained at $100 \mathrm{MHz}$ using an $8.2 \mu \mathrm{s} 90^{\circ}$ pulse width and an $18091.4 \mathrm{~Hz}$ spectral window; 17424 transients were averaged to obtain good signal to noise ratio. The residual $\mathrm{CHCl}_{3}$ solvent peak at $7.27 \mathrm{ppm}$ was used as reference in the ${ }^{1} \mathrm{H}$ spectrum while in the ${ }^{13} \mathrm{C}$ experiment the $\mathrm{CDCl}_{3}$ solvent peak at $77.23 \mathrm{ppm}$ was used as reference. Data processing was done using Varian VNMR software on a SUN workstation.

2D NMR experiments. The gradient assisted heteronuclear multiple quantum coherence ${ }^{4}$ (gHMQC) spectrum was collected with ${ }^{1} \mathrm{H}$ and ${ }^{13} \mathrm{C} 90^{\circ}$ pulse widths of 11.5 and $34 \mu \mathrm{s}$, respectively, a relaxation delay of $0.9 \mathrm{~s}$; a delay of $1 /\left[2 x^{1} \mathrm{~J}_{\mathrm{CH}}\right]$ (where ${ }^{1} \mathrm{~J}_{\mathrm{CH}}=160 \mathrm{~Hz}$ ) was used to optimize the intensity of cross-peaks from one-bond ${ }^{13} \mathrm{C}-{ }^{1} \mathrm{H}$ correlations; the spectral widths were 1200.2 $\mathrm{Hz}$ in the ${ }^{1} \mathrm{H}$ dimension and $26402.6 \mathrm{~Hz}$ in the ${ }^{13} \mathrm{C}$ dimension. The acquisition time was $0.05 \mathrm{~s}$ with ${ }^{13} \mathrm{C}$ GARP decoupling; 32 transients were averaged for each of the $2 \times 1024$ increments using the States method ${ }^{5}$ of phase sensitive detection. Processing was done using the sine-bell and shifted sine-bell weighting functions. For coherence selection, gradients were applied for $1 \mathrm{~ms}$ with gradient strengths of $0.2 \mathrm{~T} / \mathrm{m}$ and $0.1 \mathrm{~T} / \mathrm{m}$, respectively. The gradient assisted heteronuclear multiple bond correlation $^{6}$ (gHMBC) spectrum was collected with $9.8 \mu \mathrm{s}$ ${ }^{1} \mathrm{H}$ and $15 \mu \mathrm{s}{ }^{13} \mathrm{C} 90^{\circ}$ pulse widths; a relaxation delay of $1.0 \mathrm{~s}$ and $0.17 \mathrm{~s}$ acquisition time; 24 transients were collected for each of $2048 \mathrm{t}_{1}$ increments. The spectral window for the ${ }^{1} \mathrm{H}$ dimension (f2) and ${ }^{13} \mathrm{C}$ (f1) dimensions were 12001.2 and $26827.6 \mathrm{~Hz}$, respectively. Similar gradients were used in the gHMBC experiment. The data were processed using sinebell and shifted sinebell weighting functions and zero filled to $16384 \times 8192$ data matrix to improve the quality of the spectra. 
NMR Analysis. The substitution pattern of the N-confused porphyrin (2) was characterized by the help of both 1D $\left({ }^{1} \mathrm{H}\right.$ and $\left.{ }^{13} \mathrm{C}\right)$ and 2D (gHMQC and gHMBC) NMR. An expansion of the aromatic region ${ }^{1} \mathrm{H}$ spectrum of $\mathbf{2}$ (Figure S1a) shows all the porphyrin and phenyl resonances except the inner $\mathrm{N}-\mathrm{H}$ and $\mathrm{C}-\mathrm{H}$ resonances, which appear at -2.2 and $-4.7 \mathrm{ppm}$, respectively. The singlet at $8.73 \mathrm{ppm}$ is the resonance arising from $\mathrm{H}_{3}$ whereas $\mathrm{H}_{7}$ and $\mathrm{H}_{18}$ appear as doublets around 9.05 and $8.95 \mathrm{ppm}$, respectively. The doublet at $8.53 \mathrm{ppm}$ is the $\mathrm{H}_{17}$ resonance, while resonances from the rest of the porphyrin protons $\left(\mathrm{H}_{8}, \mathrm{H}_{12}\right.$, and $\left.\mathrm{H}_{13}\right)$ are not resolved and appear as overlapping multiplets between 8.47 and $8.51 \mathrm{ppm}$. The two peaks at 7.88 and $7.85 \mathrm{ppm}$ are the resonances of the para protons $\left(\mathrm{H}_{\alpha}\right.$ and $\left.\mathrm{H}_{\alpha}\right)$ of the di-tert-butylphenyl moieties. The resonances at 8.18 and $8.23 \mathrm{ppm}$ are attributed to the ortho protons $\left(\mathrm{H}_{\beta}\right.$ and $\left.\mathrm{H}_{\beta}\right)$. The two doublets centered at 8.66 and 8.65 are the resonances of meta protons $\left(\mathrm{H}_{\mathrm{x}}\right.$ and $\left.\mathrm{H}_{\mathrm{x}}\right)$ with respect to the porphyrin ring. Finally, the triplet centered at $8.38 \mathrm{ppm}$ is actually two doublets originating from $\mathrm{H}_{\mathrm{y}}$ and $\mathrm{H}_{\mathrm{y}}$. The ${ }^{13} \mathrm{C}$ spectrum of $\mathbf{2}$ (Figure $\mathrm{S} 1 \mathrm{~b}$ ) shows a number of resonances between 100 and 160 ppm that can be unambiguously assigned only with the help of $2 \mathrm{D}{ }^{1} \mathrm{H}-{ }^{13} \mathrm{C}$ correlation experiments.

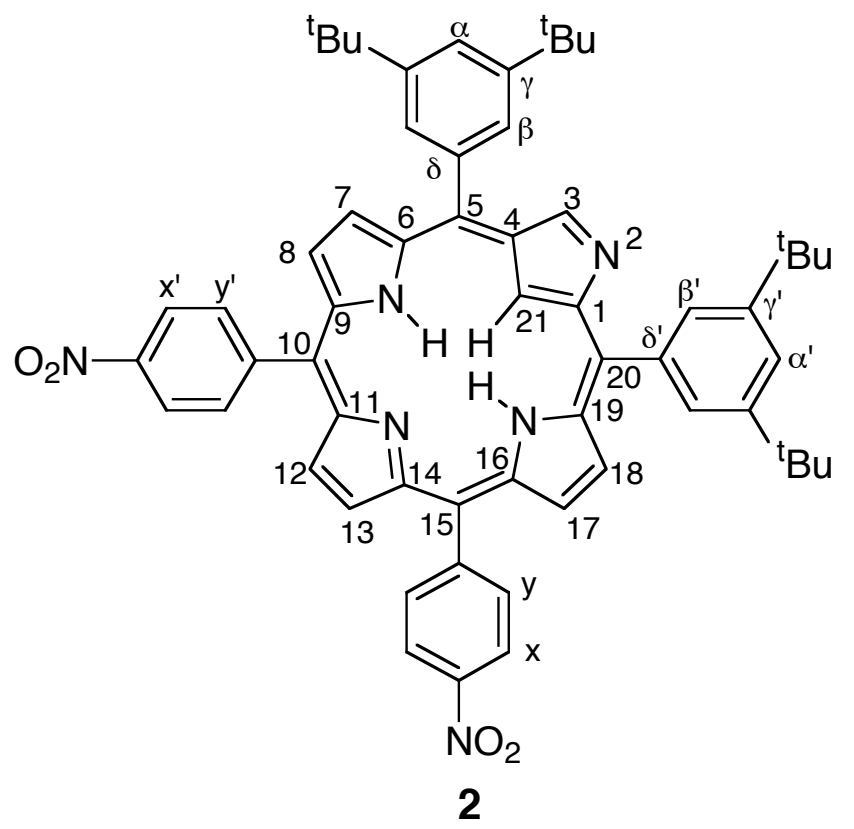



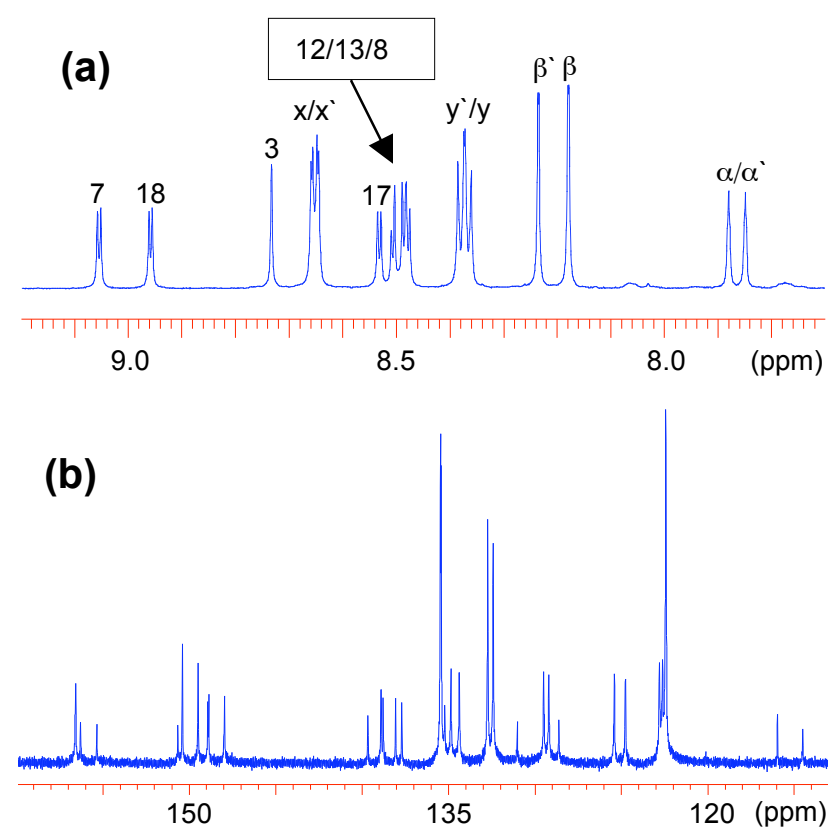

Figure S1. The $1 \mathrm{D}{ }^{1} \mathrm{H}(\mathrm{a}, 750 \mathrm{MHz})$ and ${ }^{13} \mathrm{C}$ spectra (b, $\left.400 \mathrm{MHz}\right)$ of $\mathrm{NCP} 2$ in $\mathrm{CDCl}_{3}$.

One-bond ${ }^{1} \mathrm{H}-{ }^{13} \mathrm{C}$ correlations were obtained from the gHMQC experiment in order to identify the proton bearing carbons of the molecule. In Figure S2a, cross-peaks B and C are from the C$\mathrm{H}$ fragments 7 and 18 as their positions in the ${ }^{1} \mathrm{H}$ dimension match with resonances of $\mathrm{H}_{7}$ and $\mathrm{H}_{18}$, respectively. The isolated peak $\mathrm{A}$ at $156.5 \mathrm{ppm}$ in the ${ }^{13} \mathrm{C}$ dimension is from $\mathrm{C}_{3}$, as the proton shift of this cross-peak matches $\mathrm{H}_{3}$. Cross-peaks D and $\mathrm{E}$ are attributed to the C-H fragments 17 and 8 , respectively, on the basis of the multiple bond correlations $\mathrm{H}_{18}-\mathrm{C}_{17}\left(18_{\mathrm{B}}\right)$ and $\mathrm{H}_{7}-\mathrm{C}_{8}\left(7_{\mathrm{B}}\right)$ in the gHMBC spectrum shown in Figure $\mathrm{S} 2 \mathrm{~b}$. Cross-peaks $\mathrm{F} / \mathrm{G}$ are the correlations of $\mathrm{C}-\mathrm{H}$ groups 12/13. Cross-peaks $\mathrm{K} / \mathrm{K}^{`}$ are from the $\mathrm{C}-\mathrm{H}$ fragments $\alpha / \alpha$ of the di-tertbutylated phenyl rings, while $\mathrm{J}$ and $\mathrm{J}^{`}$ are attributed to the $\beta / \beta^{`} \mathrm{C}-\mathrm{H}$ groups. Finally, the gHMQC cross-peaks I and H represent the meta (yy') and ortho (xx`) C-H fragments in the two nitrophenyl groups. 


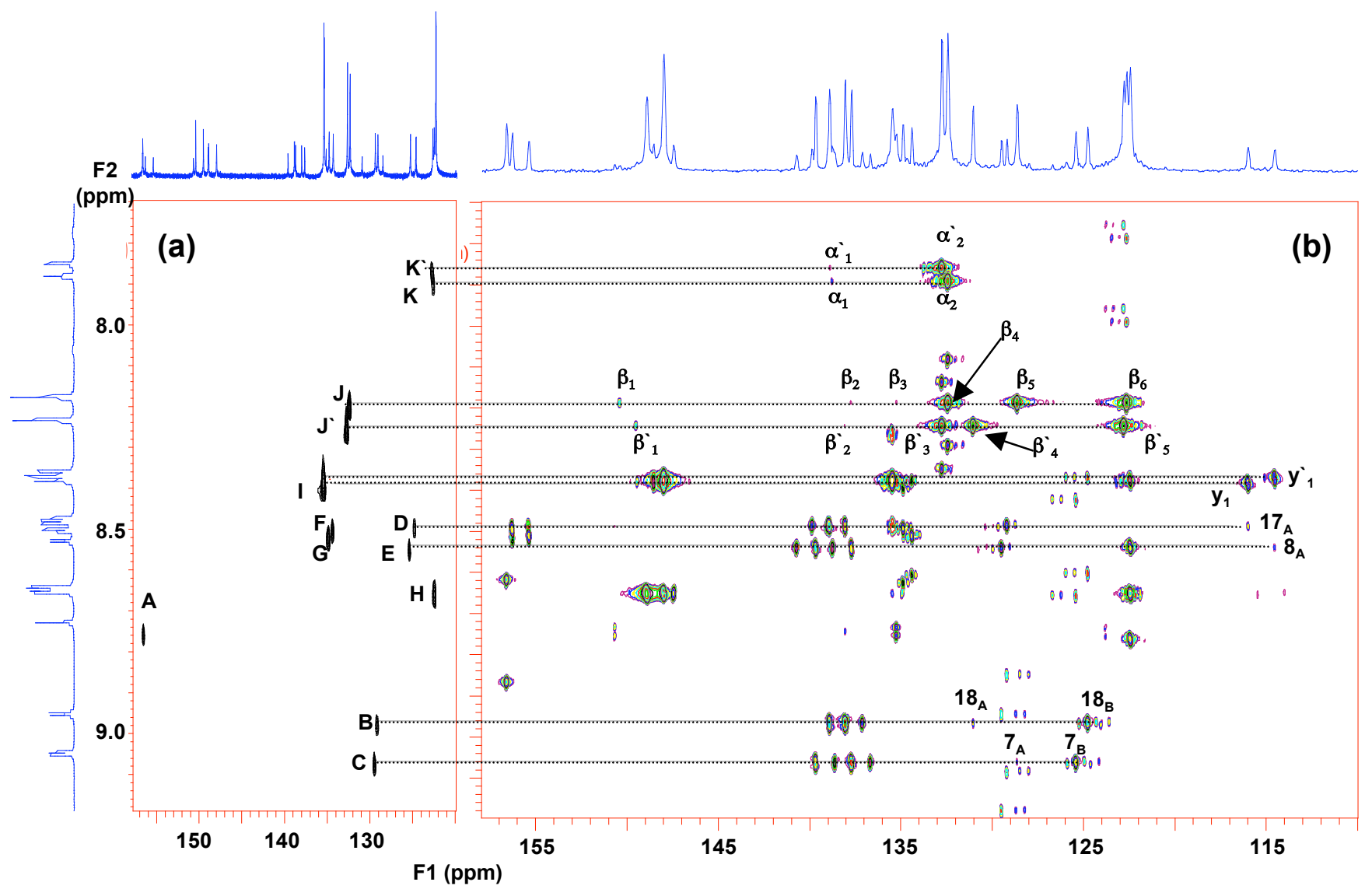

Figure S2. The 2D ${ }^{1} \mathrm{H}-{ }^{13} \mathrm{C}$ gHMQC-gHMBC correlation for the downfield region of NCP 2 acquired at $750 \mathrm{MHz}$ in $\mathrm{CDCl}_{3}$ : (a) gHMQC spectrum, (b) gHMBC spectrum.

Although the gHMQC spectrum provides assignments of the proton bearing carbon resonances, it is insufficient to determine the substitution pattern of the porphyrin ring itself, and multiple bond $\mathrm{C}-\mathrm{H}$ correlations are necessary to fully identify the structure. Figure S2b shows some of the important multiple bond correlations. For simplicity, the one-bond correlations are shown on the left side in Figure $\mathrm{S} 2 \mathrm{a}$. In the experiment, a delay of $1 / 2 \mathrm{~J}_{\mathrm{CH}}$ (based on $\mathrm{J}_{\mathrm{CH}}=8 \mathrm{~Hz}$ ) was used to optimize the intensities of cross-peaks from three-bond ${ }^{1} \mathrm{H}-{ }^{13} \mathrm{C}$ couplings. Correlations from other types of couplings also appear but are weak in intensity. The para protons $\alpha$ and $\alpha$ show two cross-peaks each, one with high intensity and other with much lower 
intensity. The high intensity cross-peaks $\alpha_{2}$ and $\alpha_{2}$ are three-bond correlations between $\mathrm{H}_{\alpha}-\mathrm{C}_{\beta}$ and $\mathrm{H}_{\alpha}{ }^{\prime}-\mathrm{C}_{\beta}$, respectively. The cross-peaks $\alpha_{1}$ and $\alpha_{1}^{\prime}$ are four-bond correlations between $\mathrm{H}_{\alpha}-\mathrm{C}_{\delta}$ and $\mathrm{H}_{\alpha}-\mathrm{C}_{\delta}$, respectively; as these are four-bond $\mathrm{C}-\mathrm{H}$ correlations, they are weaker than the threebond correlations. The $\mathrm{H}_{\beta}$ resonance yields six different cross-peaks, of which three are high intensity $\left(\beta_{4}, \beta_{5}\right.$ and $\left.\beta_{6}\right)$, one is medium intensity $\left(\beta_{1}\right)$ and the other two are very low intensity $\left(\beta_{2}\right.$ and $\left.\beta_{3}\right) . \quad \beta_{1}$ is the two-bond correlation between $\mathrm{H}_{\beta}-\mathrm{C}_{\gamma}$, while $\beta_{4}$ is the correlation between $\mathrm{H}_{\beta}-\mathrm{C}_{\beta}$ that is three bonds away. Cross-peak $\beta_{6}$ is also a three-bond correlation between $\mathrm{H}_{\beta}-\mathrm{C}_{\alpha}$. The very intense cross-peak $\beta_{5}$ must be a three-bond correlation from $\mathrm{H}_{\beta}$ to the only remaining carbon that is three bonds away $\mathrm{C}_{5}$, that is the point of attachment of the phenyl moiety to the macrocycle. The same carbon at $128.6 \mathrm{ppm}$ also shows strong HMBC correlation with the inner $\mathrm{H}_{21}\left(21_{\mathrm{A}}\right.$ in Figure $\left.\mathrm{S} 1 \mathrm{~b}\right)$ and $\mathrm{H}_{7}\left(7_{\mathrm{A}}\right)$. This carbon is three bonds away from $\mathrm{C}_{\beta}, \mathrm{C}_{21}$ and $\mathrm{C}_{7}$, and must be $\mathrm{C}_{5}$. Hence, the di-tert-butylphenyl group is attached to 2 at $\mathrm{C}_{5}$. The very low intensity cross-peaks $\beta_{2}$ and $\beta_{3}$ are attributed to four-bond correlations between $\mathrm{H}_{\beta}-\mathrm{C}_{6}$ and $\mathrm{H}_{\beta}-\mathrm{C}_{4}$, respectively. Similarly, $\mathrm{H}_{\beta^{\prime}}$ exhibits high intensity $\mathrm{HMBC}$ cross-peaks with $\mathrm{C}_{\alpha^{\prime}}\left(\beta_{5}^{\prime}{ }_{5}\right)$ and $\mathrm{C}_{\beta^{\prime}}$ $\left(\beta_{3}^{\prime}\right)$. The cross-peak $\beta_{1}^{\prime}$ is the two-bond correlation between $\mathrm{H}_{\beta} \cdot \mathrm{C}_{\gamma^{\prime}}$. The high intensity crosspeak $\beta_{4}$ arises from the porphyrin ring carbon to which the phenyl ring is attached. As in case of $\mathrm{H}_{\gamma}$, the resonance from this carbon at $131.0 \mathrm{ppm}$ also shows strong HMBC correlation with the inner $\mathrm{C}_{21}\left(21_{\mathrm{B}}\right.$ in Figure $\left.\mathrm{S} 1 \mathrm{~b}\right)$ and $\mathrm{C}_{18}\left(18_{\mathrm{A}}\right)$, and so must be $\mathrm{C}_{20}$. Moreover, the point of attachment of the nitrophenyl groups can be proven by the HMBC correlation between $\mathrm{H}_{\mathrm{y}}-\mathrm{C}_{15}$ $\left(\mathrm{y}_{1}\right)$ and $\mathrm{H}_{\mathrm{y}^{\prime}}-\mathrm{C}_{10}\left(\mathrm{y}_{1}^{\prime}\right)$. The cross-peaks $\mathrm{y}_{1}$ and $\mathrm{y}_{1}^{\prime}$ also show three-bond correlations with $\mathrm{H}_{17}$ $\left(17_{\mathrm{A}}\right)$ and $\mathrm{H}_{8}\left(8_{\mathrm{A}}\right)$, respectively.

Figure S3 shows regions from the HMQC and HMBC correlations to the inner $\mathrm{H}_{21}$ resonance. From the one-bond correlation spectrum in Figure S3a, the carbon resonance at $101 \mathrm{ppm}$ can be assigned to $\mathrm{C}_{21}$. In Figure $\mathrm{S} 3 \mathrm{~b}$, the HMBC cross-peak $21_{\mathrm{E}}$ is the three-bond correlation between 
resonance $\mathrm{H}_{21}$ and $\mathrm{C}_{3}$, while $21_{\mathrm{D}}$ is the correlation between the resonance of $\mathrm{H}_{21}$ and $\mathrm{C}_{1}$. Crosspeak $21_{\mathrm{C}}$ can be attributed to the two-bond correlation between the resonances of $\mathrm{H}_{21}$ and $\mathrm{C}_{4}$. Hence, we can identify the unique correlations necessary to prove the substitution pattern shown in $\mathbf{2}$, with the di-tert-butyl containing phenyl groups are attached at $\mathrm{C}_{5}$ and $\mathrm{C}_{20}$ and the nitrophenyl groups attached at $\mathrm{C}_{10}$ and $\mathrm{C}_{15}$. Based upon the similarities in the NMR spectra $(1 \mathrm{H}$ and 13C) between 2 and $\mathbf{3}-\mathbf{4}$, the regiochemistry of the latter NCPs is assumed to be similar to that of 2.

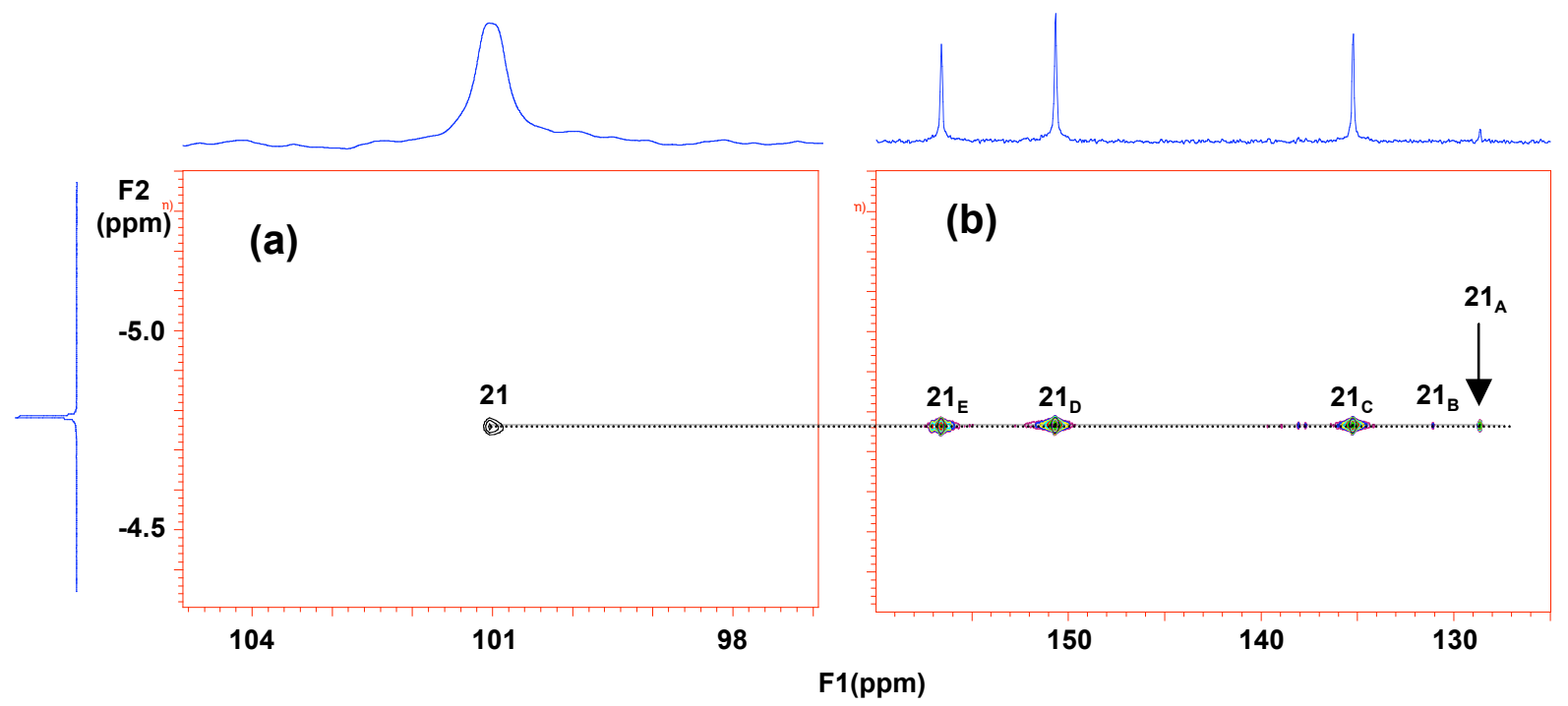

Figure S3. The 2D ${ }^{1} \mathrm{H}^{13} \mathrm{C}$ gHMQC-gHMBC correlation for the upfield region of NCP 2 acquired at $750 \mathrm{MHz}$ in $\mathrm{CDCl}_{3}$ : (a) gHMQC spectrum, (b) gHMBC spectrum. 

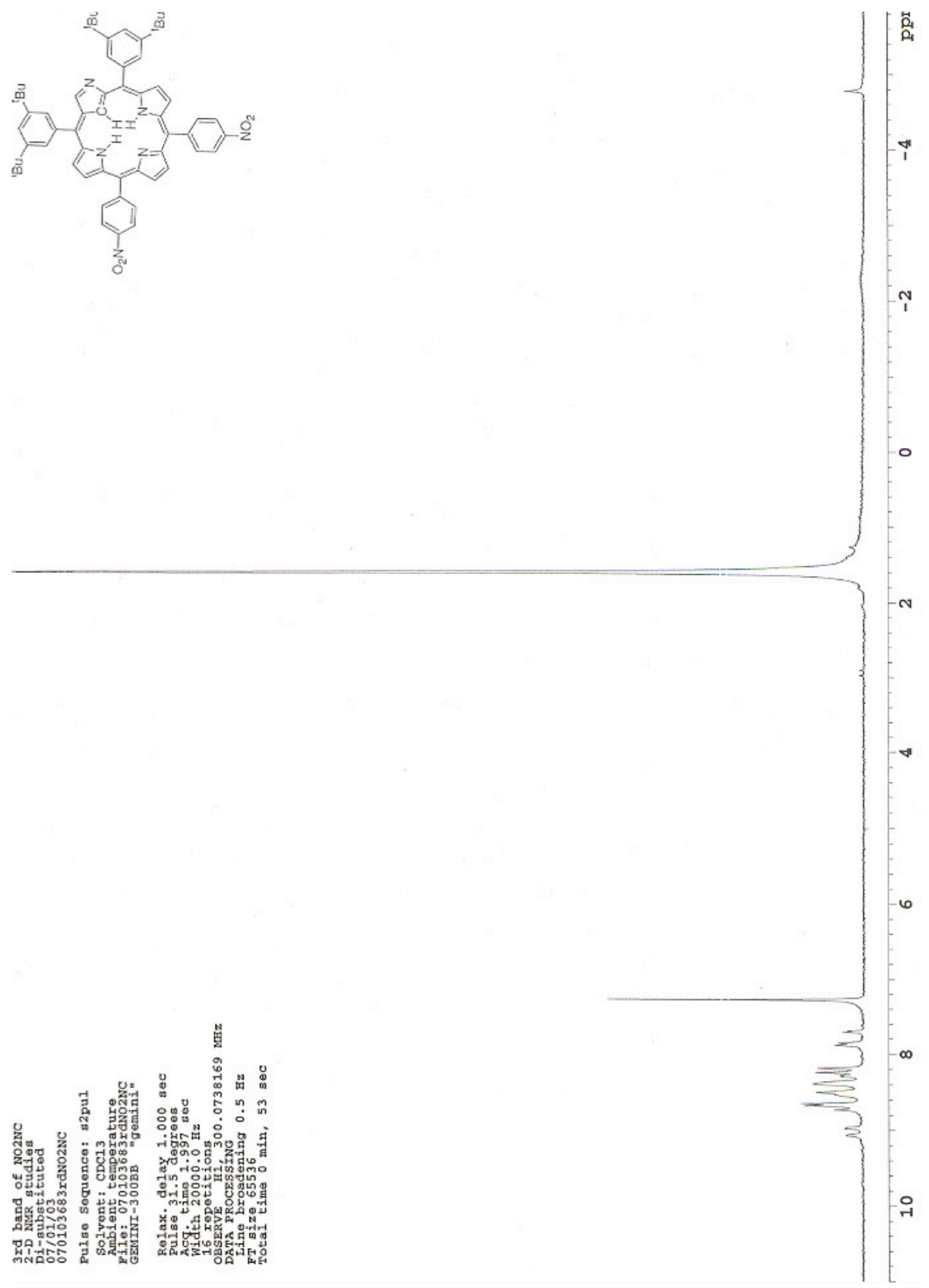


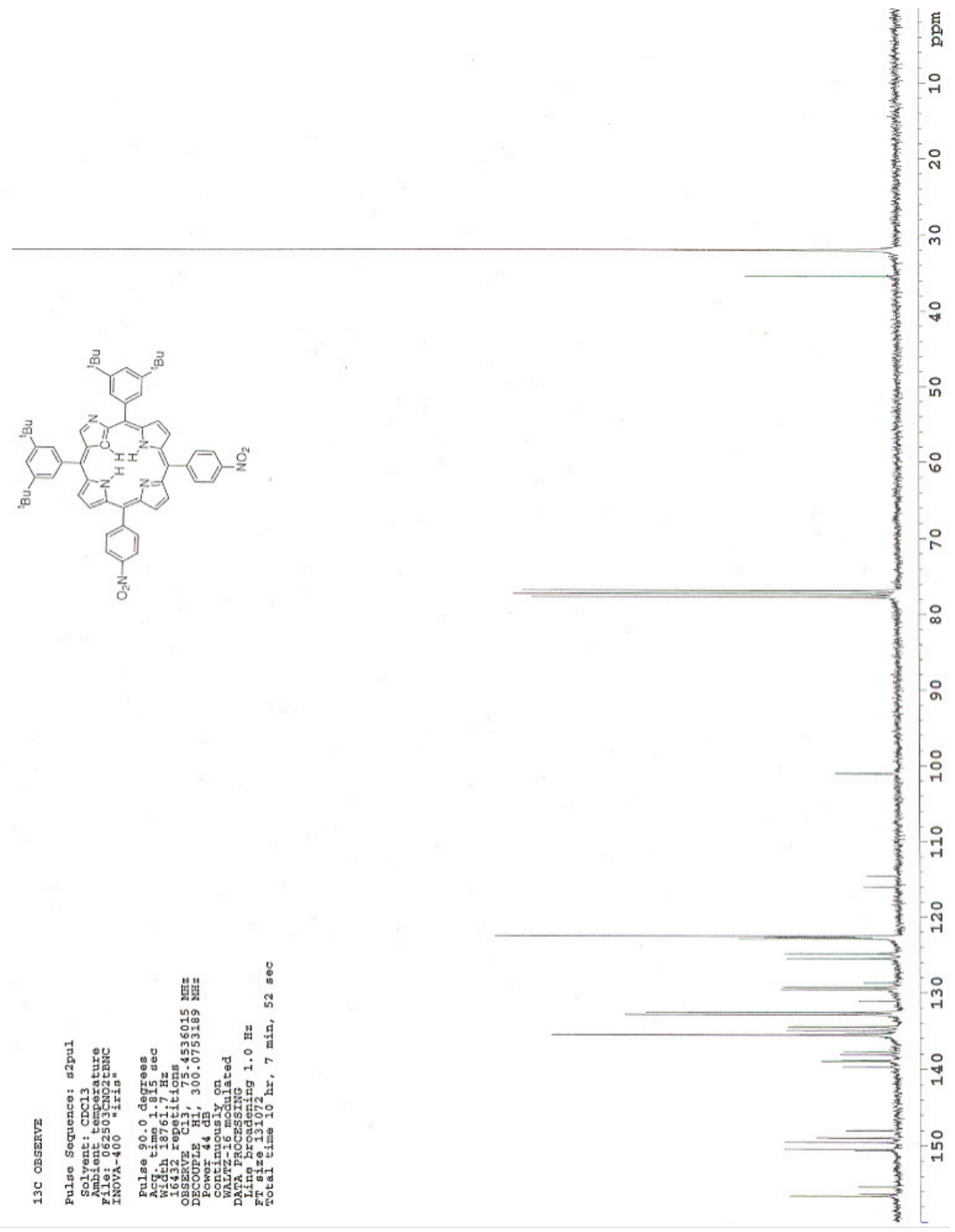




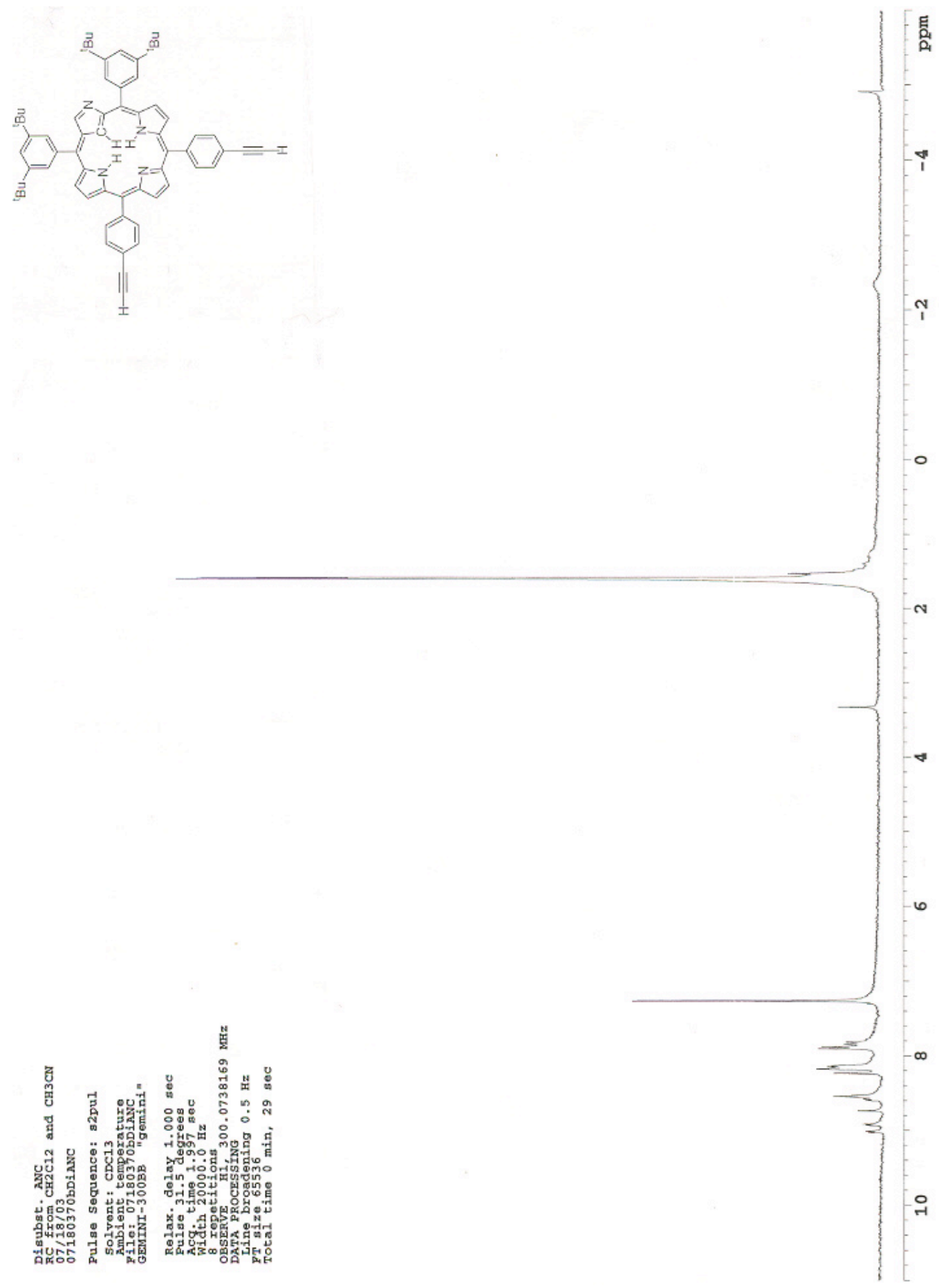




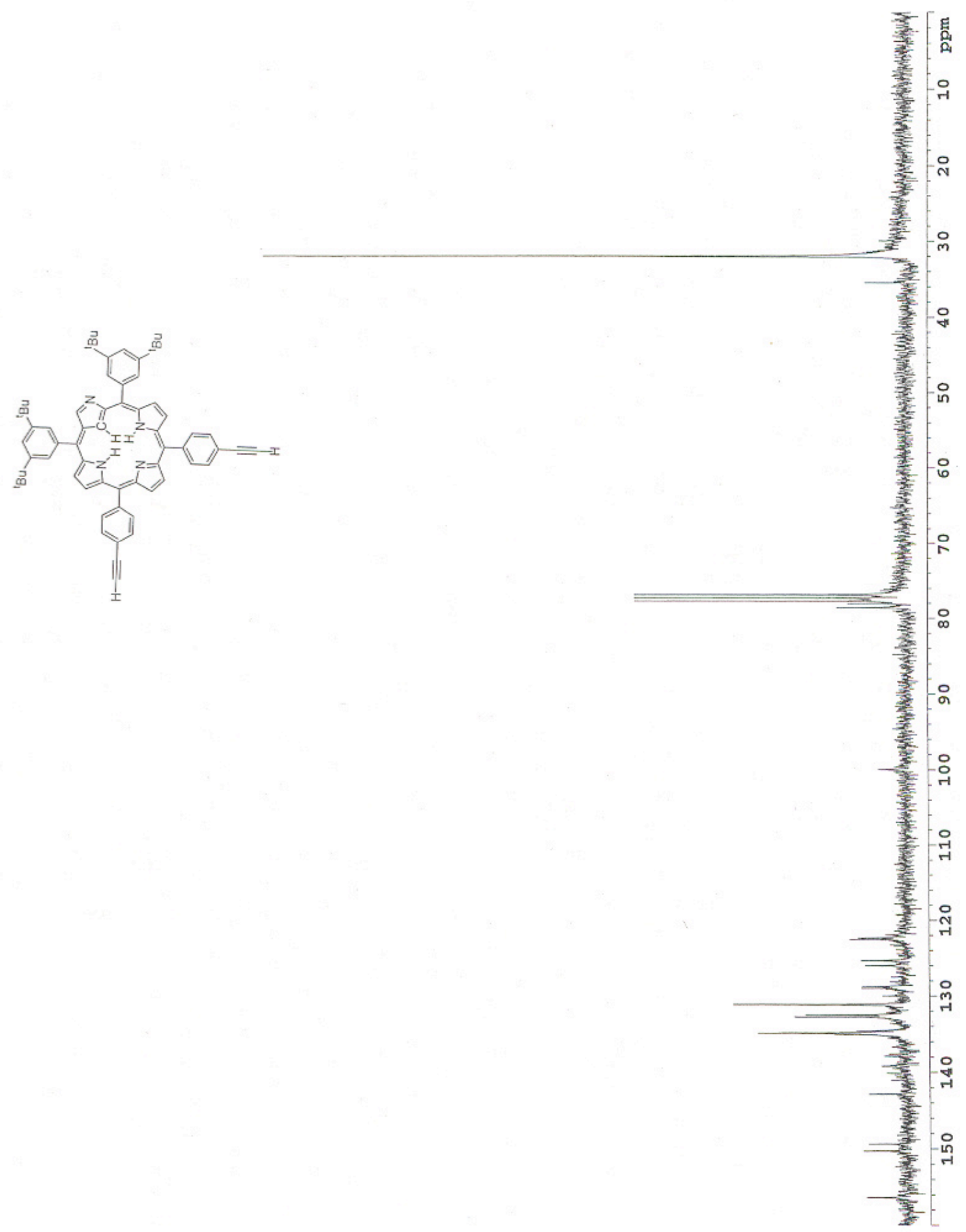



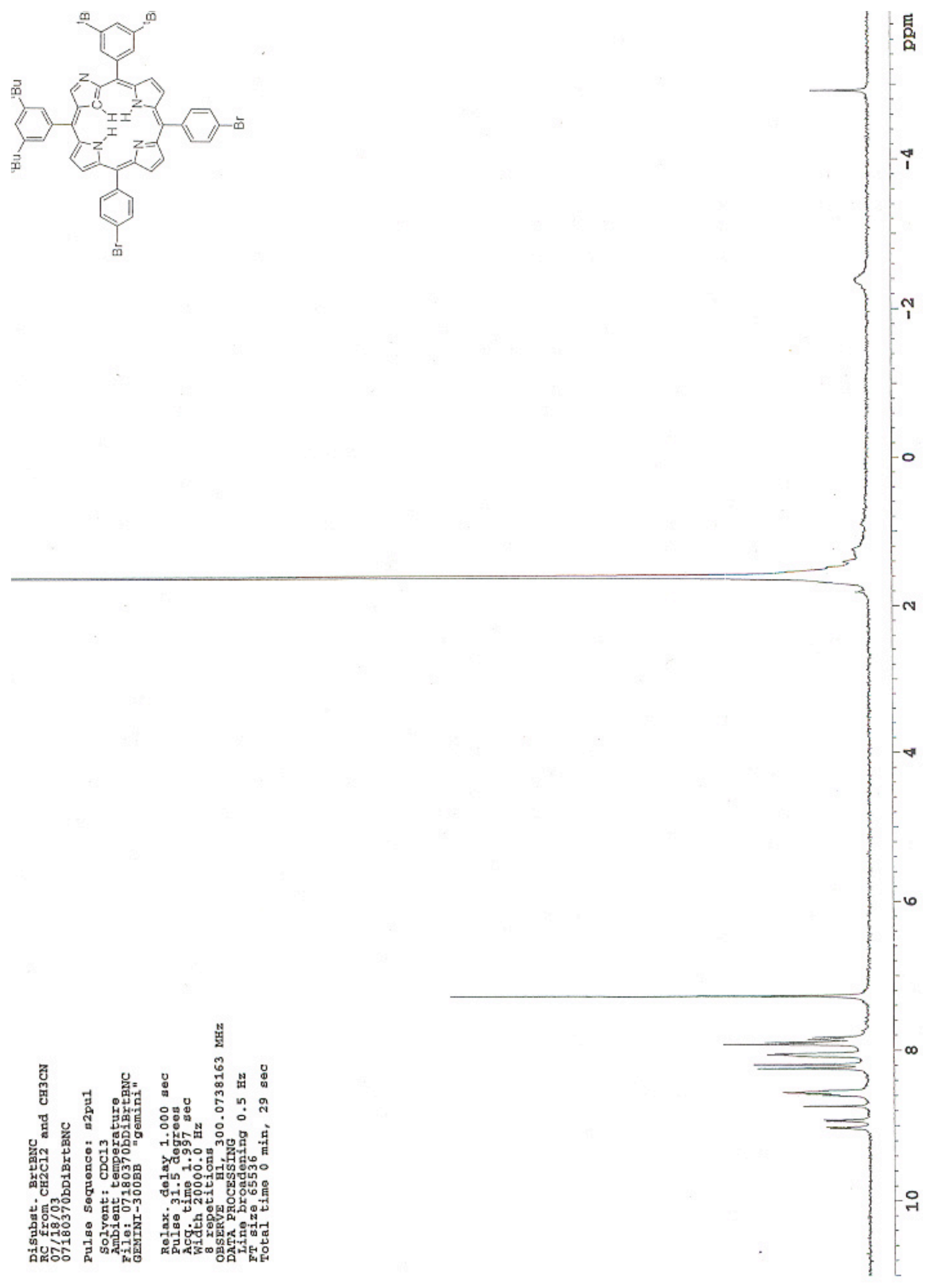


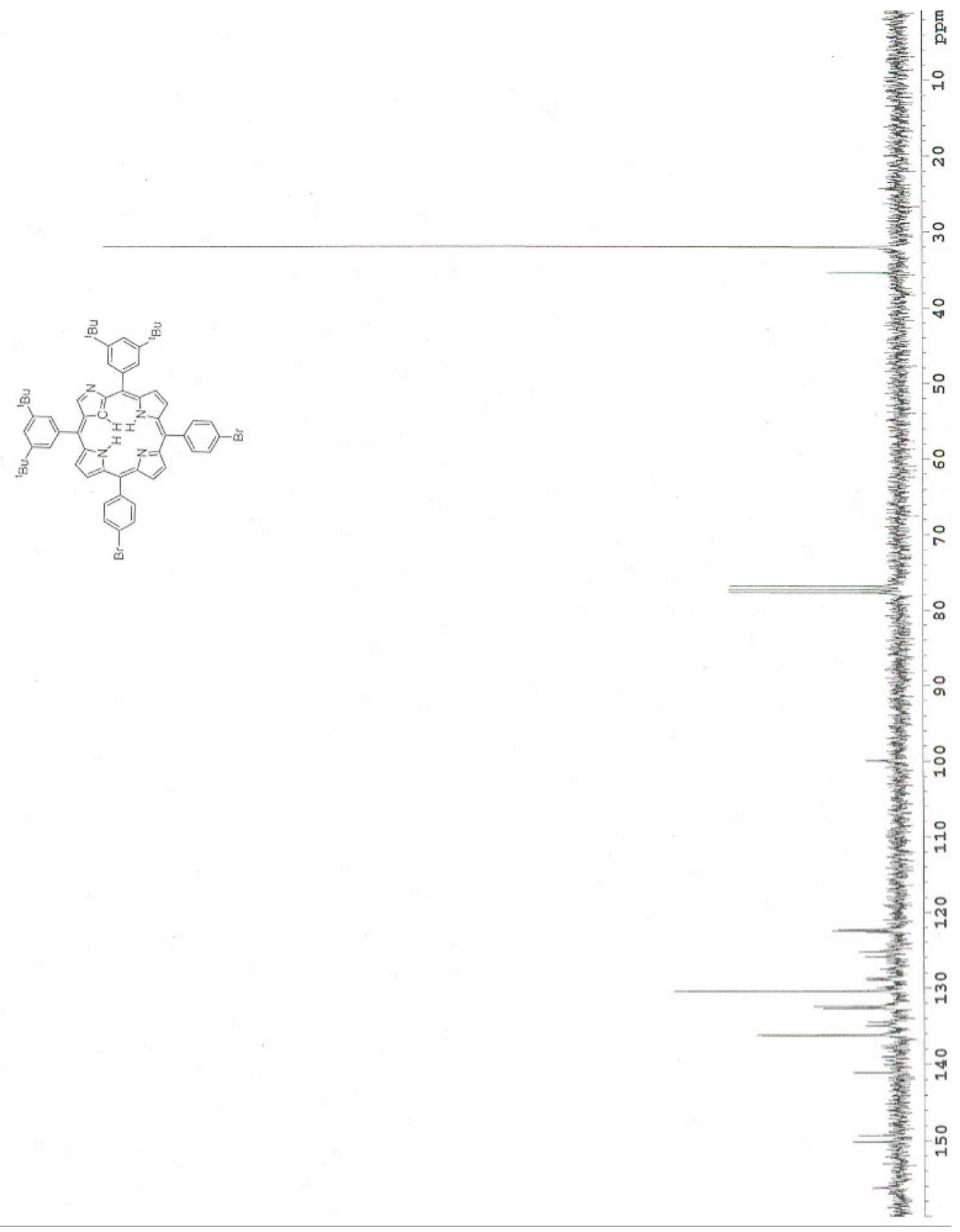




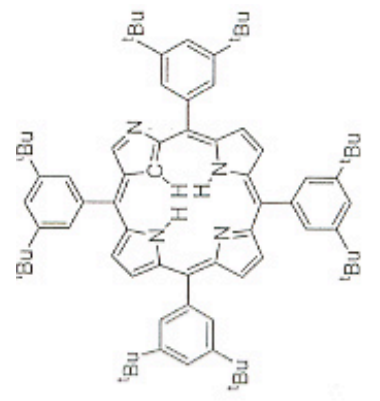




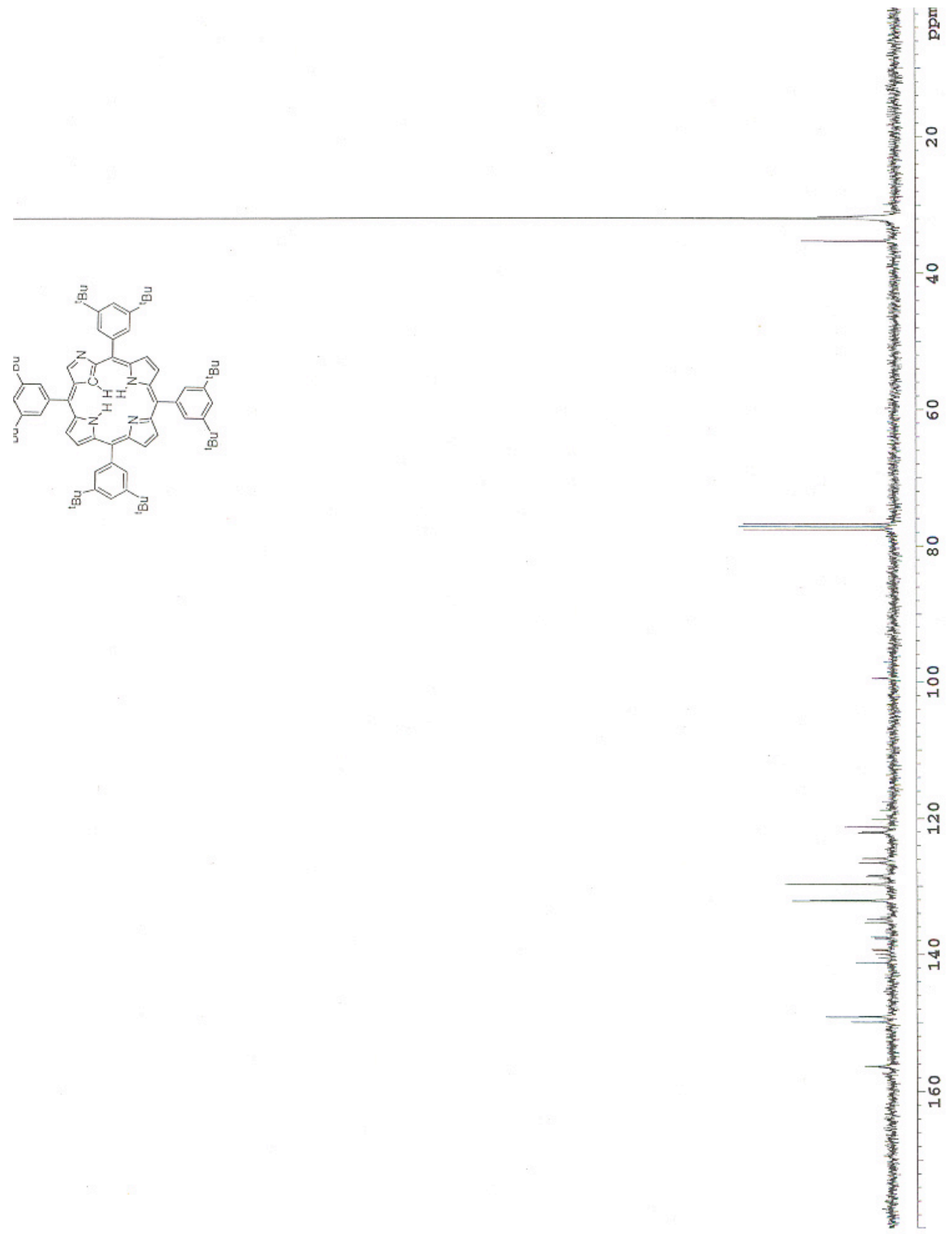



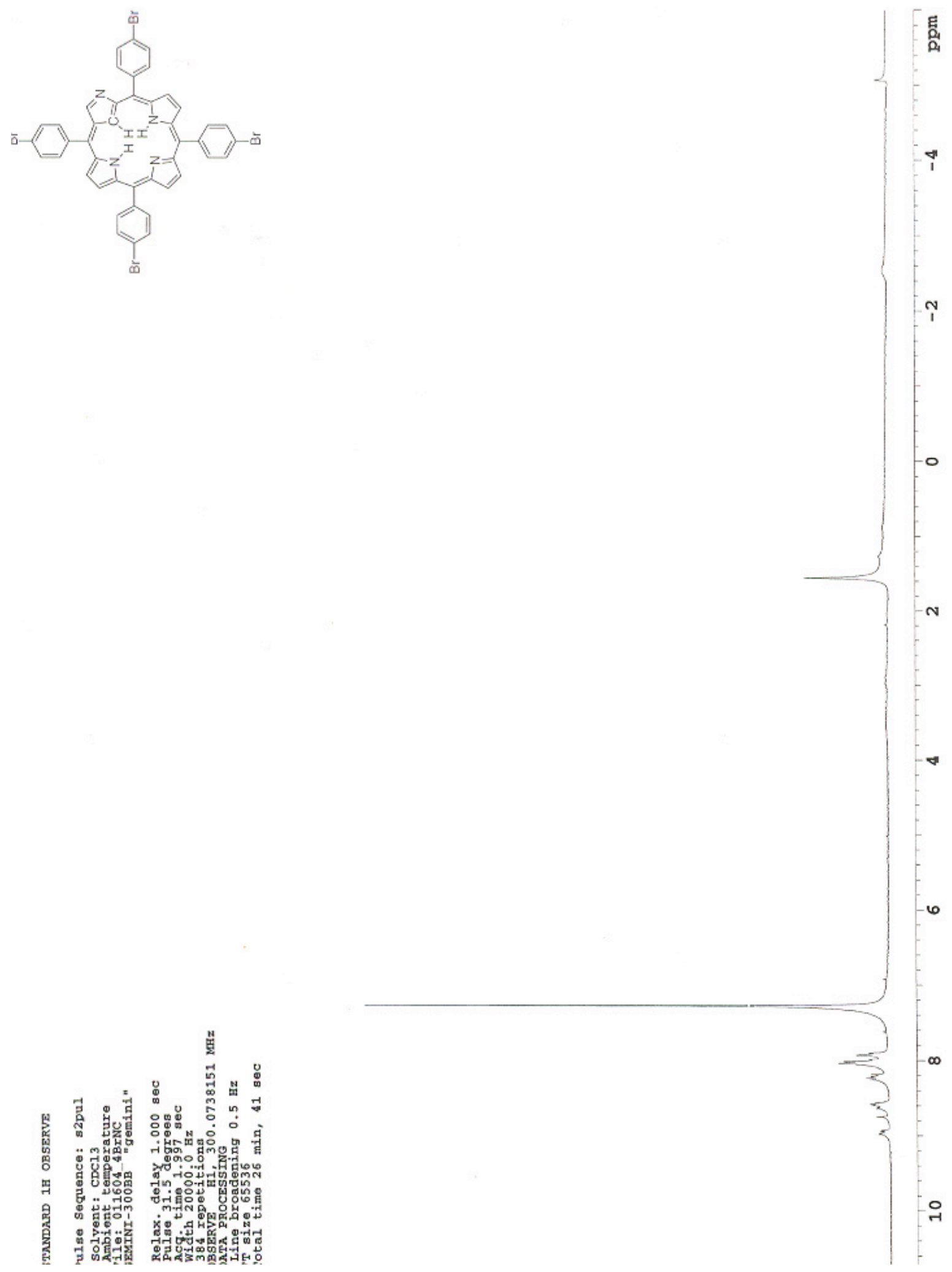


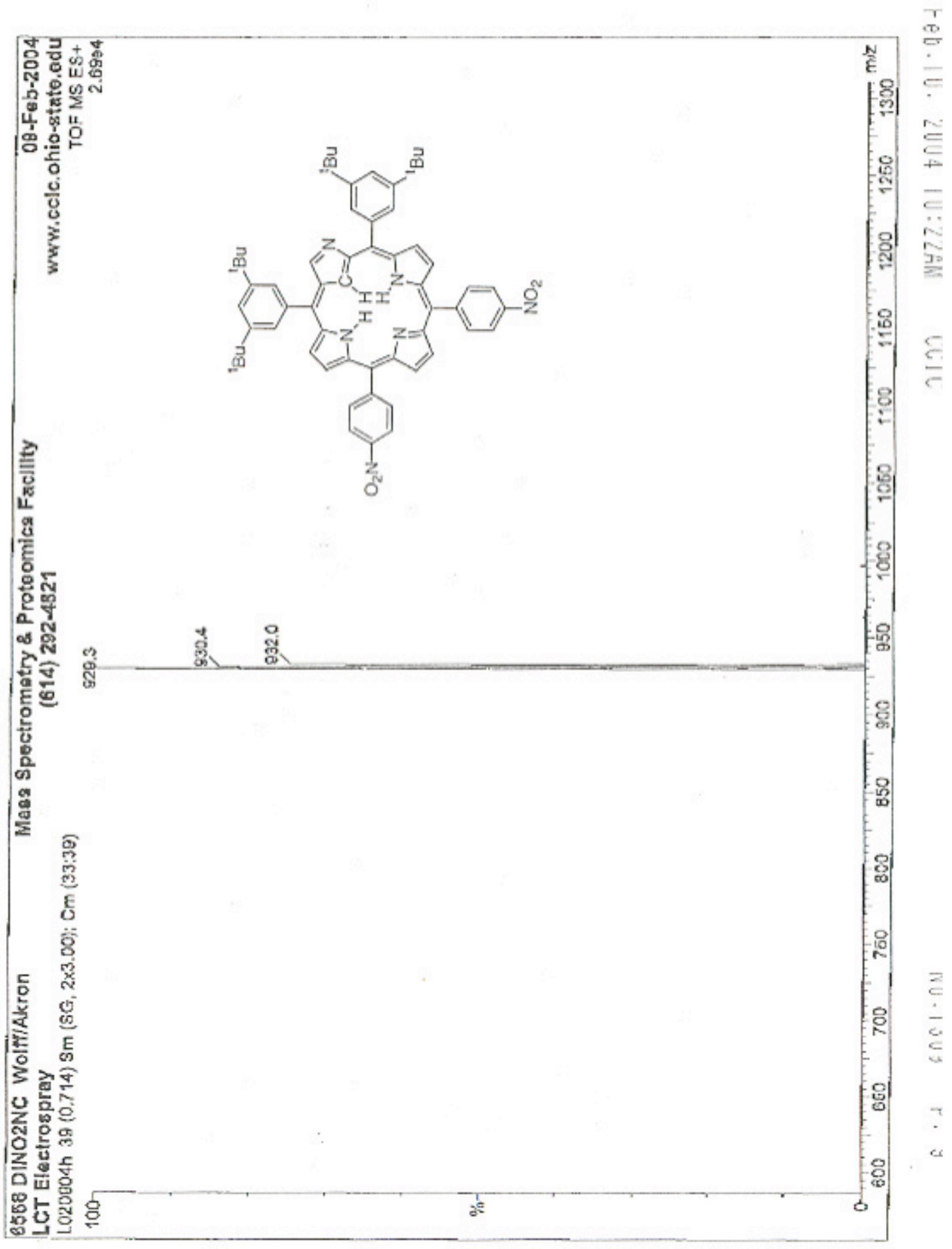




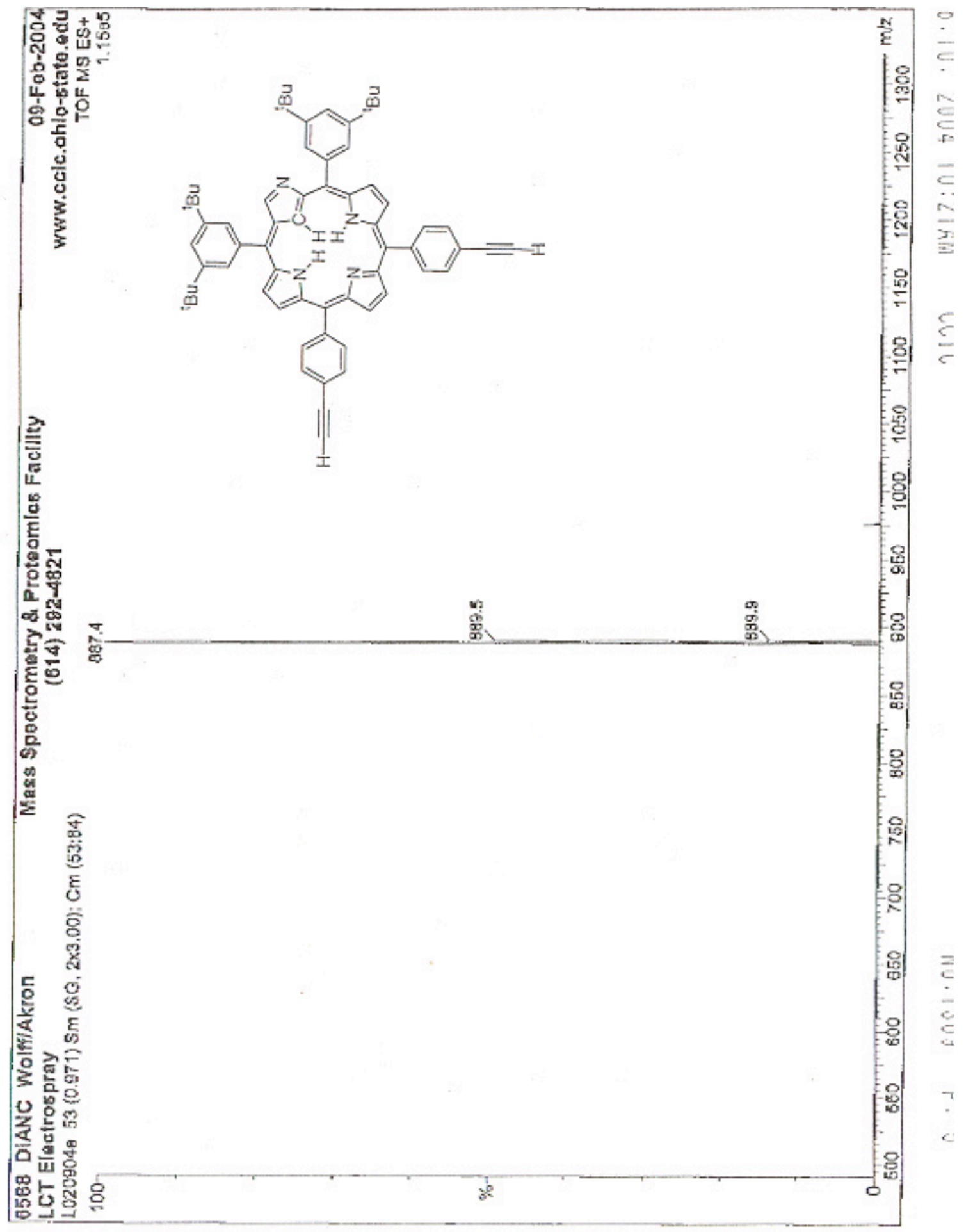




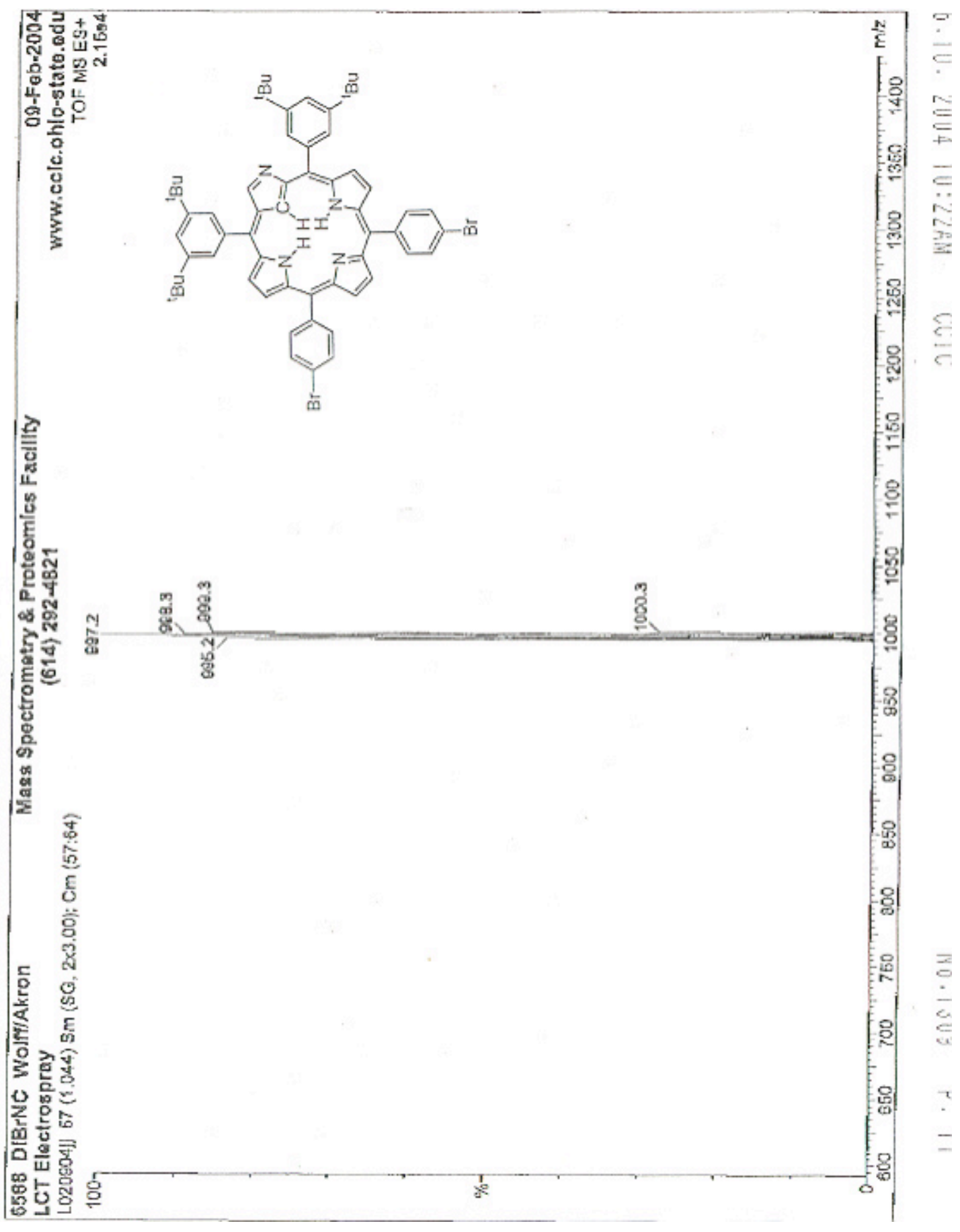




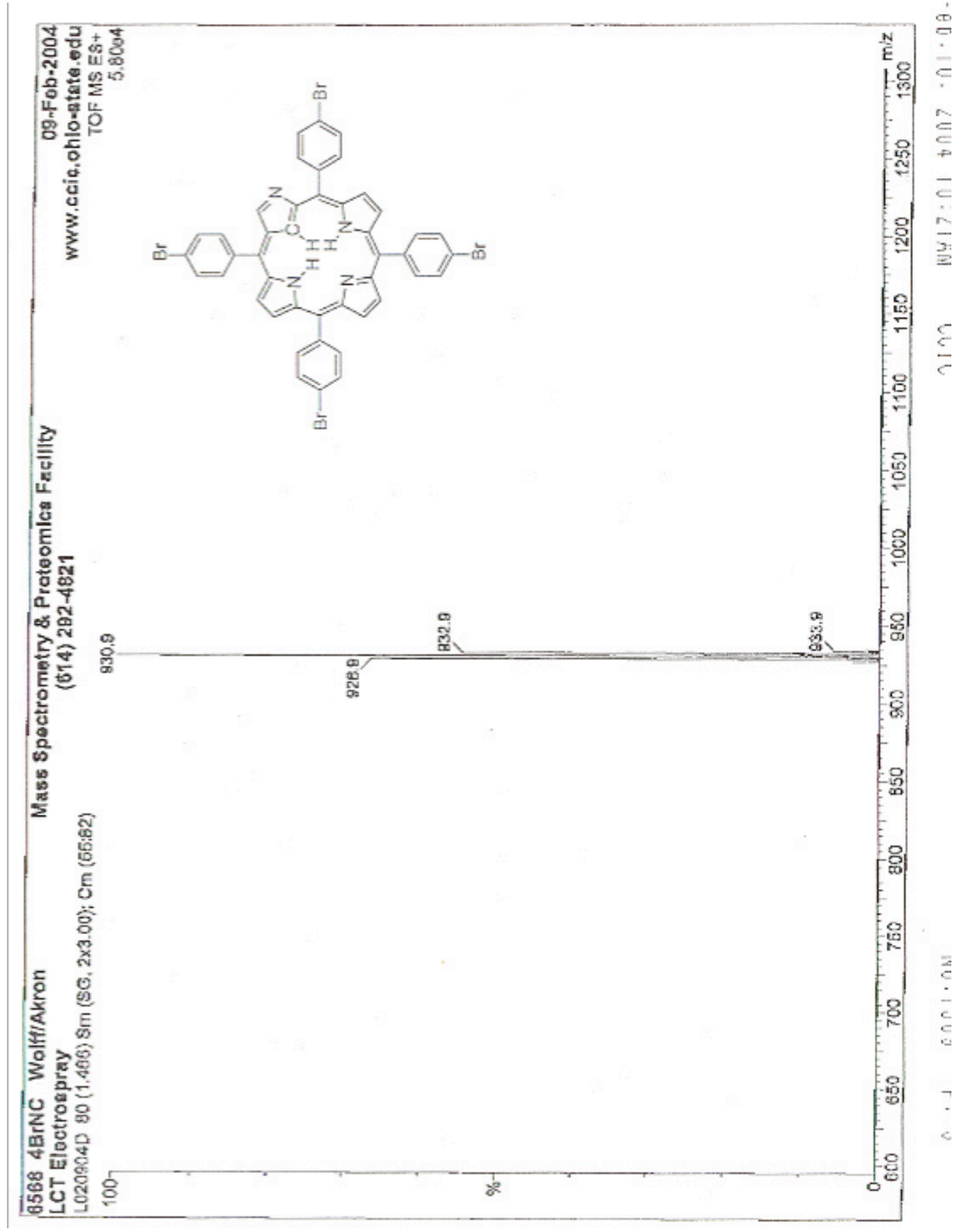




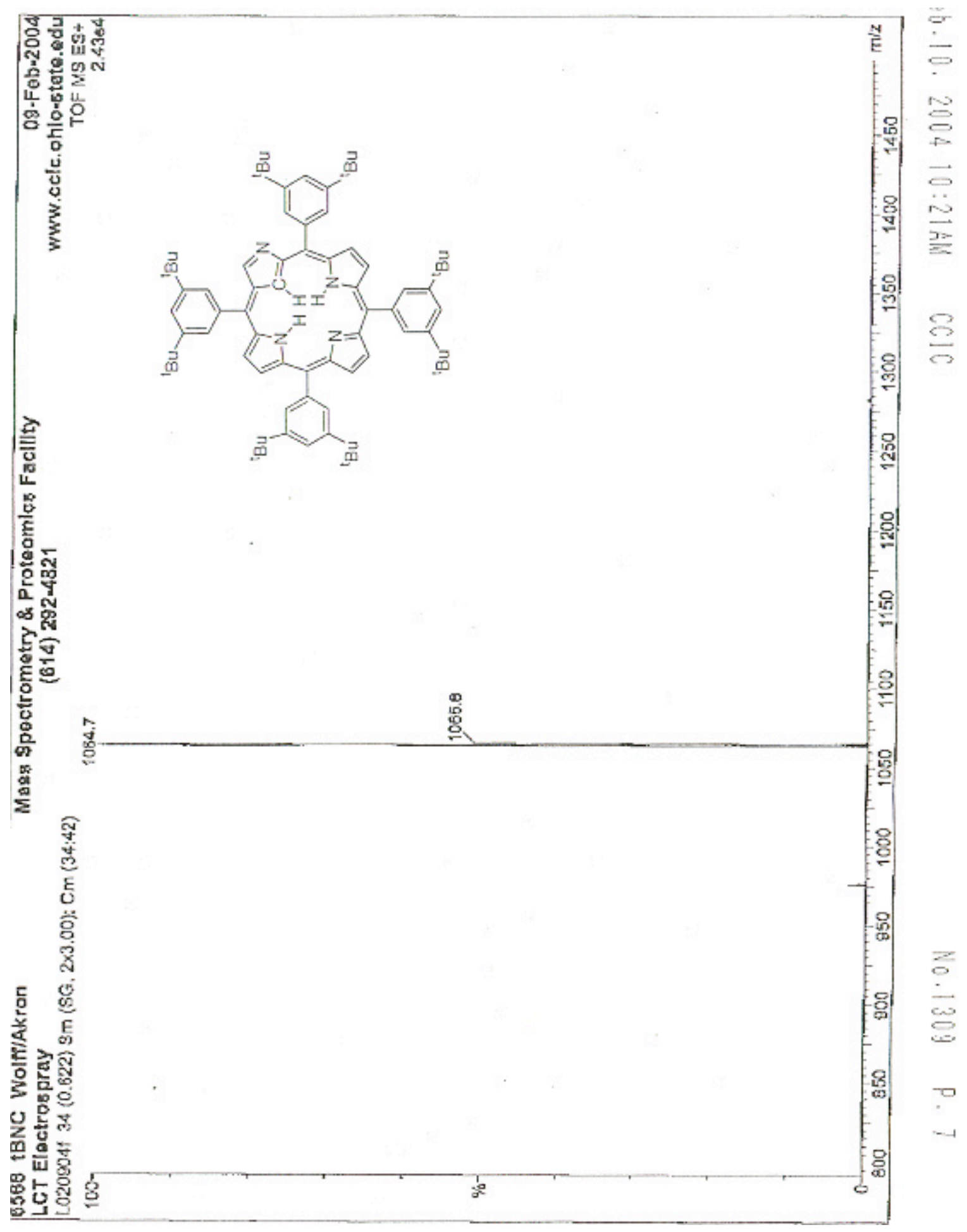

\footnotetext{
${ }^{1}$ Belair, J.P.; Ziegler, C.S.; Rajesh, C.S.; Modarelli, D.A. J. Phys. Chem. A 2002, 106, 64456451.
} 
${ }^{2}$ Strachan, J.P.; Gentemann, J.S.; Kalsbeck, W.A.; Lindsey, J.S.; Holten, D.; Bocian, D.F. J. Am. Chem. Soc. 1997, 119, 11191.

${ }^{3}$ The structure of this compound has been previously published (Ariga, K.; Kunitake, T.; Furuta, H. J. Chem. Soc., Perkin Trans. 2, 1996, 667-672) but no synthetic or absorption/fluorescence details were reported.

${ }^{4}$ Tyburn, J. M.; Brereton, I. M.; Doddrell, D. M. J. Magn. Reson. 1992, 97, 305.

${ }^{5}$ States, D. J.; Haberkorn, R. A.; Ruben, D. J. J. Magn. Reson. 1982, 48, 286.

${ }^{6}$ Summers, M. F.; Marzilli, L. G.; Bax, A. J. Am. Chem. Soc. 1986, 108, 4285. 